\title{
FATTY ACID COMPOSITION OF LIPIDS OF BULL, BOAR, RABBIT AND HUMAN SEMEN
}

\author{
B. AHLUWALIA* AND R. T. HOLMAN \\ Worcester Foundation for Experimental Biology, \\ Shrewsbury, Massachusetts, and \\ Hormel Institute, University of Minnesota, Austin, Minnesota
}

(Received 16th April 1968, revised 26th August 1968)

\begin{abstract}
Summary. Bull, boar, rabbit and human semen was fractionated into seminal plasma, sperm tails and sperm heads. The fatty acid composition of total lipid, phospholipid, phosphatidyl choline, triglycerides and diglycerides was determined in each fraction. Qualitative and quantitative differences in the fatty acid contents were found between the species and between the semen fractions. Bull and rabbit seminal plasma contained relatively higher proportions of polyunsaturated acids (PUFA) ( $\omega 6$ and $\omega 3$ ) than that of man and boar. The sperm tails contained in all four species more PUFA than did the sperm heads. The higher metabolites of oleic acid were not present in measurable amounts. The 20- and 22-carbon acids were present in semen in much larger quantities than thus far reported, in any other mammalian tissue.
\end{abstract}

\section{INTRODUCTION}

Spermatozoa contain a considerable amount of intracellular lipid (Miescher, 1897; Zittle \& O'Dell, 1941; Lovern, Olley, Hartree \& Mann, 1957; Miller, 1960) which is thought to act as a source of energy (Lardy \& Phillips, 1941; Hartree \& Mann, 1961; Miller, Bertek \& Mayer, 1960). Some data are available on the composition of lipid and fatty acids in testicular and ejaculated ram spermatozoa (Scott, Voglmayr \& Setchell, 1967), and in the spermatozoa and seminal plasma of bull, boar and stallion (Komarek, Pickett, Lanz \& Jensen, 1964; Komarek, Pickett, Gibson \& Jensen, 1965a; Komarek, Pickett, Gibson \& Lanz, 1965b). Flipse \& Porter (1955) identified short chain fatty acids in bull semen. Volatile fatty acids were found in semen of dog, bull, ram, fowl, stallion and man (Scott, White \& Annison, 1960). Dietz, Pickett, Komarek \& Jensen (1963) and Miller (1960) reported on the fatty acid composition of bull semen, but fatty acids with 20- and 22-carbon atoms were not reported in their analyses, although studies from this laboratory showed reproductive tissues to be particularly rich in such acids (Holman \& Hofstetter, 1965). Because lipids are abundant in parts of cellular structure (Locke, 1964), and because some fatty

* Present address : Building 10, Room 5N-102, National Institutes of Health, Bethsheda, Maryland 20014. 
acids, being oxidizable, may serve as an important source of energy for spermatozoa (Mann, 1964; Scott \& Dawson, 1968), the fatty acid composition of semen was re-investigated in detail, using the technique of gas-liquid chromatography (GLC). Samples of semen from four species including man were fractionated, and the composition of total lipid and of major lipid components was determined in each fraction.

\section{MATERIALS AND METHODS}

Human semen was obtained from a group of healthy donors; four pooled samples, $25 \mathrm{ml}$ each, were collected over a period of about 1 month, and shipped to the laboratory in the frozen state. Four pooled samples of $15 \mathrm{ml}$ of semen were collected from four groups of thirty New Zealand rabbits; the semen was collected artificially twice or thrice a week from each group. Six composite samples of the sperm-rich semen portion were collected from six Yorkshire boars of good fertility. Six pooled samples of $15 \mathrm{ml}$ of semen were obtained from

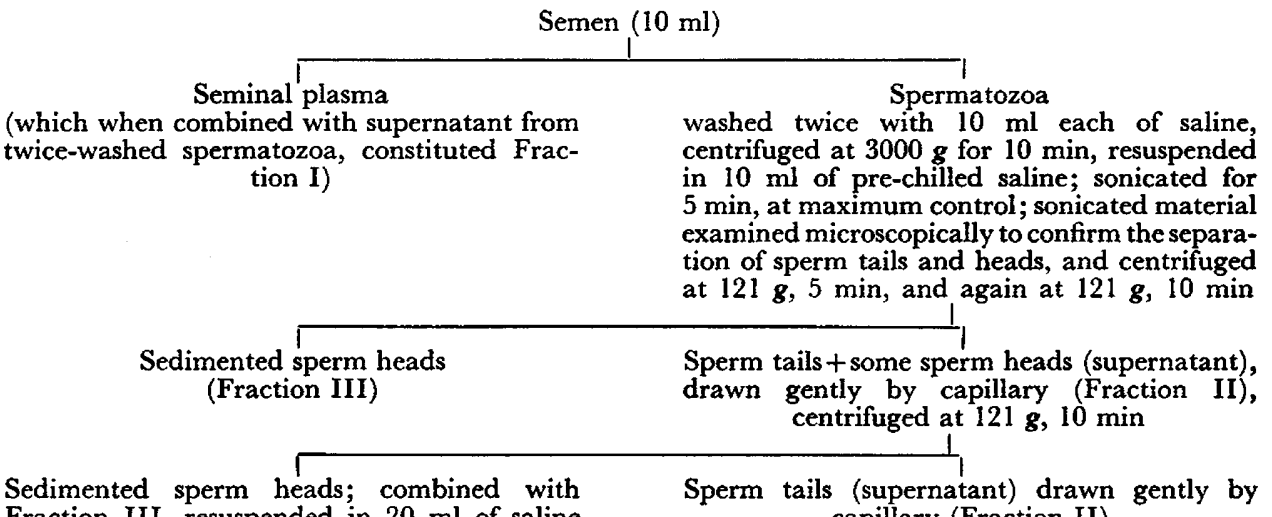

Fraction III, resuspended in $20 \mathrm{ml}$ of saline capillary (Fraction II)

Text-fig. 1. Procedure for the separation of sperm heads and sperm tails.

six Holstein bulls of good fertility record. Before analysis, the semen was thawed and centrifuged at $4000 \mathrm{~g}$ for $15 \mathrm{~min}$ at $4^{\circ} \mathrm{C}$. The seminal plasma was decanted and the spermatozoa were washed twice with $10 \mathrm{ml}$ of physiological saline and recentrifuged. A detailed procedure for the separation of sperm heads and tails is given in Text-fig. 1. The purity of the fractions was estimated by microscopic examinations to be more than $90 \%$. The fractions representing the seminal plasma (Fraction I), sperm tails (Fraction II) and heads (Fraction III) were lyophilized for $12 \mathrm{hr}$ before lipid extraction. This procedure is a modification of the method described by Zittle \& O'Dell (1941) and Nelson (1954). No attempt was made to separate the midpieces from the sperm tails.

The lipids were extracted from each fraction with chloroform:methanol (2:1). An aliquot of the extracted lipid was separated into neutral lipids and phospholipids by column chromatography (Hanahan, Dittmer \& Warashina, 1957). The purity of each fraction was monitored by thin-layer chromatography (TLC). The phospholipid fraction was separated into various subcomponents 
by TLC in a solvent system of chloroform:methanol:water $(65: 35: 4)$. Only the major phospholipid component, corresponding to phosphatidyl choline ('lecithin'), was scraped off and eluted with the same solvent system that was used for phospholipid on TLG. Hartree \& Mann (1961) reported that in ram semen the phosphatidyl choline component contained also the choline-based plasmalogen. It is probable, therefore, that the lecithin component which we isolated by the TLC procedure also contained the plasmalogen.

The other components, such as phosphatidyl ethanolamine, phosphatidyl serine and phosphatidyl inositol, constituting together only about $35 \%$ of total phospholipid, were not separated for fatty acid analysis. The identification of the phospholipid components was carried out by comparison with known standards on the TLG plate (available from Applied Science Laboratories, College Park, Pa.). Similarly, the neutral lipid fraction obtained by means of column chromatography was separated into various subclasses on TLG plates using 70:25:2 petroleum ether:diethyl ether:acetic acid as solvent system. The major components, triglycerides and diglycerides, were scraped from the TLC plates and eluted with the solvent that was used for separation of neutral lipids on TLC. The minor fractions of cholesterol esters, free fatty acids and methyl esters were not isolated for the fatty acid analysis. The lipid components were trans-esterified using $5 \% \mathrm{HCl}$ in methanol, and the methyl esters were analysed by GLC using a Beckman GC2A gas chromatograph with flame ionization detector, and a column packed with $20 \%$ ethylene glycol succinate and $2 \%$ phosphoric acid (Ahluwalia \& Holman, 1966). Methyl esters in excess of $10 \%$ of total fatty acids were isolated on preparative GLC and hydrogenated to determine the chain length.

\section{RESULTS AND DISCUSSION}

In human semen, the fatty acid composition of total lipid, phospholipid, phosphatidyl choline (lecithin), triglyceride and diglyceride was determined using the three main fractions; that is, seminal plasma, sperm heads and sperm tails. Only data for lecithin and triglycerides are presented in Table 1. They indicate that both seminal plasma and spermatozoa are relatively rich in polyunsaturated fatty acids (PUFA). Almost all the known metabolites of linoleic acid and linolenic acid were present in measurable amounts in human semen. The higher metabolites of oleic acid $(18: 1 \omega 9)$ were, however, not detectable in human semen, although in animal reproductive organs, e.g., bovine and swine testes and ovaries (Holman \& Hofstetter, 1965) the 20:1 $\omega 9,20: 2 \omega 9,22: 3 \omega 9$ and $22: 4 \omega 9$ acids were reported to be present in measurable amounts.

Similar analyses were made on the main three fractions from semen of bulls, boars and rabbits. The fatty acids were qualitatively the same, but differed in quantity. Data relating to polyunsaturated derivatives of linoleic $\omega 6)$ and linolenic $(\omega 3)$ acids in lecithin and triglycerides are given in Table 1. These data show that long chain PUFA are abundant in seminal lipids. In fact, the sum of $\omega 6$ and $\omega 3$ acids accounts for up to $63 \%$ of the lecithin fatty acids in bull seminal plasma (see also Text-fig. 2). PUFA ranged from 12 to $65 \%$ of the total fatty acid content in the semen fractions from all four species. The sperm 
TABLE 1

FATTY AGID COMPOSITION OF LEGITHIN AND TRIGLYGERIDES OF SEMINAL PLASMA, SPERM TAILS AND SPERM HEADS OF HUMAN SEMEN

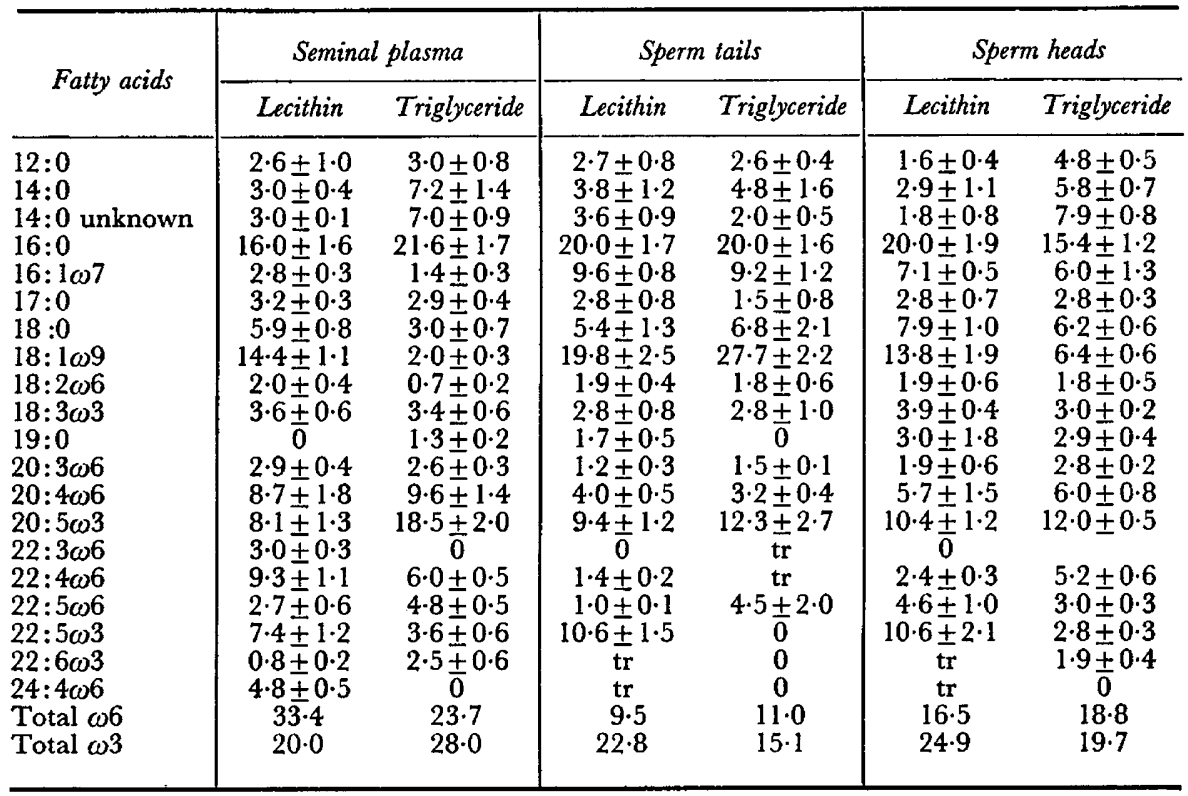

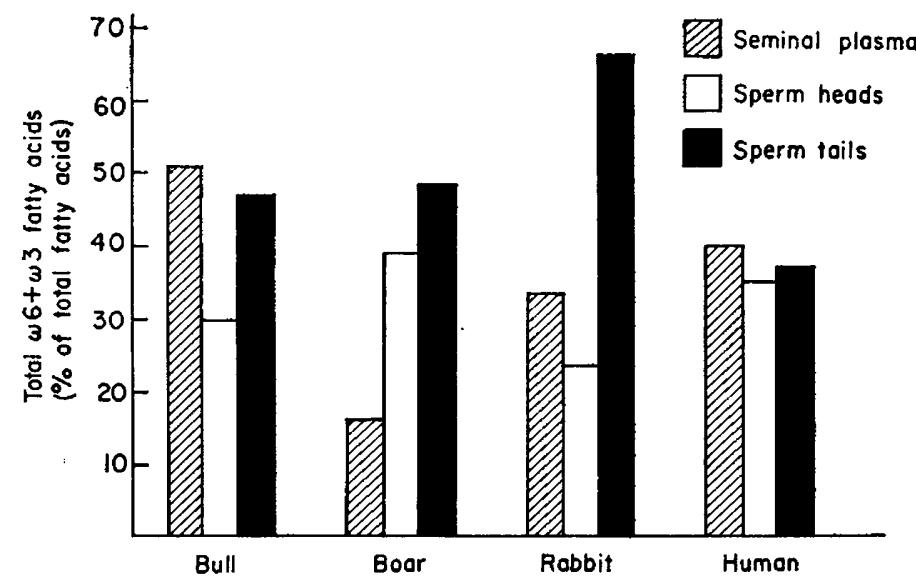

TExT-FIG. 2. Fatty acids derived from linoleic and linolenic acid expressed as a percentage of the total fatty acids present in lipids of fractions obtained from bull, boar, rabbit and human semen. 
tails were especially rich in PUFA, particularly so in the rabbit. In all cases, the percentage of PUFA in the total fatty acids of sperm heads was less than in the sperm tails.

In the bull, the total lipids were relatively richer in total $\omega 3+\omega 6$ fatty acids in the seminal plasma and sperm tails than in the sperm heads (see Text-fig. 2). In the boar and rabbit semen, however, the total lipids of sperm tails contained the largest proportion of the polyunsaturated acids. In the sperm tails from bull spermatozoa, the percentage of $\omega 6$ fatty acids in the total lipid was 18:2, $5 \cdot 2 \% ; 20: 3,3.6 \% ; 20: 4,3.6 \% ; 22: 3,0.6 \% ; 22: 4,13.5 \%$; and $22: 5,1.6 \%$; making a total of $28 \%$. The percentage of $\omega 3$ acids was $18: 3,1.6 \% ; 20: 5$, $0.8 \% ; 22: 5,20.8 \%$; and $22: 6$, trace; making a total of $23 \%$. In general,

TABLE 2

THE PERGENTAGE OF POLYUNSATURATED FATTY ACIDS IN SEMINAL LIPID FRACTIONS

\begin{tabular}{|c|c|c|}
\hline & Total $\omega 6$ acids & Total $\omega 3$ acids \\
\hline $\begin{array}{l}\text { Bull } \\
\quad \text { Seminal plasma: lecithin } \\
\text { triglycerides }\end{array}$ & $\begin{array}{l}35 \cdot 1 \\
17 \cdot 6\end{array}$ & $\begin{array}{l}28 \cdot 4 \\
\operatorname{tr}\end{array}$ \\
\hline $\begin{array}{l}\text { Sperm tail: lecithin } \\
\text { triglycerides }\end{array}$ & $\begin{array}{l}26 \cdot 5 \\
10 \cdot 0\end{array}$ & $\begin{array}{r}30 \cdot 6 \\
5 \cdot 7\end{array}$ \\
\hline $\begin{array}{l}\text { Sperm head: lecithin } \\
\text { triglycerides }\end{array}$ & $\begin{array}{l}25 \cdot 8 \\
14.7\end{array}$ & $\begin{array}{r}28 \cdot 3 \\
1 \cdot 6\end{array}$ \\
\hline $\begin{array}{l}\text { Boar } \\
\text { Seminal plasma: lecithin } \\
\text { triglycerides }\end{array}$ & $\begin{array}{r}25 \cdot 1 \\
7 \cdot 7\end{array}$ & $\begin{array}{l}7 \cdot 5 \\
1 \cdot 3\end{array}$ \\
\hline 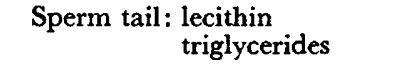 & $\begin{array}{l}33 \cdot 4 \\
10 \cdot 0\end{array}$ & $\begin{array}{r}13 \cdot 3 \\
2 \cdot 6\end{array}$ \\
\hline 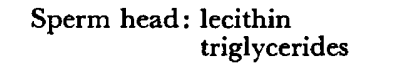 & $\begin{array}{r}35 \cdot 1 \\
7 \cdot 5\end{array}$ & $\begin{array}{l}9 \cdot 0 \\
5 \cdot 2\end{array}$ \\
\hline $\begin{array}{l}\text { Rabbit } \\
\quad \text { Seminal plasma: lecithin } \\
\text { triglycerides }\end{array}$ & $\begin{array}{l}25 \cdot 3 \\
16 \cdot 0\end{array}$ & $\begin{array}{r}13 \cdot 6 \\
5 \cdot 3\end{array}$ \\
\hline $\begin{array}{l}\text { Sperm tail : lecithin } \\
\text { triglycerides }\end{array}$ & $\begin{array}{l}25 \cdot 2 \\
33 \cdot 0\end{array}$ & $\begin{array}{l}19 \cdot 4 \\
18 \cdot 3\end{array}$ \\
\hline $\begin{array}{l}\text { Sperm head: lecithin } \\
\text { triglycerides }\end{array}$ & $\begin{array}{l}17 \cdot 6 \\
24 \cdot 9\end{array}$ & $\begin{array}{l}11 \cdot 7 \\
16 \cdot 3\end{array}$ \\
\hline
\end{tabular}

linoleic acid and arachidonic acid are the major $\omega 6$ acids in mammalian tissues, including reproductive organs, and the $\mathrm{C}_{22}$ metabolites of $\omega 6$ acids are usually the minor components. Bull semen contained unusually large quantities of acids related to linolenic acid $(18: 3 \omega 3)$; together, the $\omega 3$ acids constituted about $23 \%$ of total acids in seminal plasma and sperm tails, and $14.0 \%$ in the sperm heads. In general, $\omega 3$ acids are the minor PUFA components in other tissues, including the reproductive organs. The presence of large amounts of long chain metabolites of $\omega 6$ and $\omega 3$ acids together with only relatively small amounts of their pre-

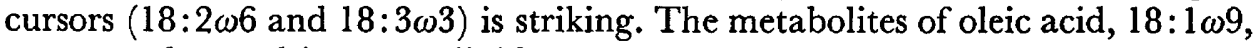
were not detected in semen lipids. 
Boar semen was less rich in PUFA than bull semen (Table 2). The higher metabolites of $\omega 6$ and $\omega 3$ acids were present in much smaller amounts in lipids of seminal plasma than in those of sperm heads and sperm tails. Similar amounts of total PUFA were present in lipids of the sperm heads. The pattern of total PUFA in the diglyceride fraction revealed a composition almost identical to that of the phospholipid fraction. Whether this represents a metabolic relationship or an artifact in the storage and preparation of the samples cannot be stated.

In rabbit semen the sperm tails contained larger amounts of $\omega 6$ and $\omega 3$ acids than did the other fractions. Most notable is the presence of large amounts of C20:5 03 which is almost $20 \%$ of total acids in total lipid, in contrast to seminal plasma and sperm head where this acid is present in small amounts, from 1 to $3 \%$ respectively. The neutral lipid fractions were relatively richer in PUFA than in other species, the triglyceride, diglyceride and phospholipid fractions containing almost identical amounts of total PUFA.

Our analyses show that each species has a distinct fatty acid pattern so far as the three semen components are concerned; that is, seminal plasma, sperm tails and sperm heads. Of particular interest are the fatty acids with 22 carbon atoms which were encountered in large quantities. For example, the 22-carbon acids $(\omega 6+\omega 3)$ in the total lipids of sperm tails were $37 \%$ for bull, $40 \%$ for boar, $20 \%$ for rabbit and 10\% for man. Bieri \& Prival (1965) found large quantities of $\mathrm{C}_{22}$ acids in the testes of rat, mouse, hamster, rabbit, dog, chicken and man. Therefore, it would seem that these fatty acids are essential constituents of reproductive organs. The rapid loss of these fatty acids in essential fatty acid deficiency in rat testes and rabbit testes accompanied by the reproductive failure, also indicates their importance in reproduction (Ahluwalia, Shima \& Pincus, 1968; Ahluwalia, Pincus \& Holman, 1967). Normally, the $\mathrm{C}_{22}$ fatty acids are synthesized from linoleic $(\omega 6)$ and linolenic $(\omega 3)$ acids by chain elongations and dehydrogenations.

\section{ACKNOWLEDGMENT}

One of the authors (B.A.) the was recipient of National Institutes of Health Fellowship 7F3-AM-23963-01Al. This study was supported in part by a grant from G. D. Searle and Company to the Worcester Foundation; U.S. Public Health Service research grants AM 03559 and AM 04524; and the Hormel Foundation.

\section{REFERENCES}

Ahluwalia, B. S. \& Holman, R. T. (1966) Fatty acid composition in bovine pre- and post-partum testes. Lipids, 1, 197.

Ahluwalia, B. S., Pincus, G. \& Holman, R. T. (1967) Essential fatty acid deficiency and its effects upon reproductive organs of male rabbits. F. Nutr. 92, 205.

Ahluwalia, B. S., Shima, S. \& Pincus, G. (1968) In vitro synthesis of androgens by testicular tissue of rat deficient in essential fatty acids. 7 . Reprod. Fert. 17, 263.

Bieri, J. G. \& Prival, E. L. (1965) Lipid composition of testes from various species. Comp. Biochem. Physiol. 15, 275.

Dietz, R. W., Picketr, B. W., Komarek, R. J. \& Jensen, R. G. (1963) Fatty acid composition of bovine semen. J. Dairy Sci. 46, 468. 
Fuipse, R. G. \& Porter, F. E. (1955) Presence of volatile fatty acids in bovine semen. Proc. Soc. exp. Biol. Med. 89, 432.

Hanahan, D. J., Dittmer, J. G. \& Warashina, E. (1957) A column chromatographic separation of classes of phospholipids. F. biol. Chem. 228, 685 .

Hartree, E. F. \& Mann, T. (1961) Phospholipids in ram semen. Metabolism of plasmalogen and fatty acids. Biochem. F. 80, 464 .

Holman, R. T. \& Hofstetter, H. H. (1965) The fatty acid composition of the lipids from bovine and porcine reproductive tissue. 7. Am. Oil Chem. Soc. 42, 540.

Komarek, R. J., Pickett, B. W., Gibson, E. W. \& Jensen, R. G. (1965a) Lipids of porcine spermatozoa, seminal plasma and gel. 7. Reprod. Fert. 9, 131.

Komarek, R. J., Pickett, B. W., Gibson, E. W. \& Lanz, R. N. (1965b) Composition of lipids in stallion semen. F. Reprod. Fert. 10, 337.

Komarek, R. J., Pickett, B. W., Lanz, R. N. \& Jensen, R. G. (1964) Lipid composition of bovine spermatozoa and seminal plasma. F. Dairy Sci. 47, 531.

LARdy, H. A. \& Phillips, P. H. (1941) Phospholipid as a source of energy for motility of bull spermatozoa. Am. 7. Physiol. 134, 542.

Locke, M. (1964) Cellular membranes in development. In: The 22nd Symposium of the Society for the Study of Development and Growth. Academic Press, New York.

Lovern, J. A., Olley, J., Hartree, E. F. \& Mann, T. (1957) The lipid of ram spermatozoa. Biochem. J. 67, 630 .

ManN, T. (1964) Biochemistry of semen and of the male reproductive tract, pp. 274-278. Wiley, New York.

MIEscher, F. (1897) Die histochemischen und physiologischen Arbeiten. Vogel, Leipzig.

MilleR, L. D. (1960) The lipids of bovine spermatozoa. University Microfilms Inc., Mic 60-4046, Ann Arbor, Michigan.

Miller, L. D., Bertek, M. \& Mayer, D. T. (1960) The lipids of bovine spermatozoa. Fedn Proc. Fedn Am. Socs exp. Biol. 19, 132.

NELSON, L. (1954) Enzyme distribution in fragmented bull spermatozoa. Biochim. biophys. Acta, 14, 312.

Scott, T. W. \& Dawson, R. M. C. (1968) Metabolism of phospholipids by spermatozoa and seminal plasma. Biochem. F. 108, 457.

Scott, T. W., Voglmayr, J. K. \& Setchell, B. P. (1967) Lipid composition and metabolism in testicular and ejaculated ram spermatozoa. Biochem. F. 102, 456.

Scott, T. W., White, I. G. \& Annison, E. F. (1960) Fatty acids in semen. Biochem. 7. 78, 740.

Zittle, C. A. \& O'Dell, R. A. (1941) Chemical studies of bull spermatozoa. Lipid, sulfur, cystine, nitrogen, phosphorus, and nucleic acid content of whole spermatozoa and of the parts obtained by physical means. J. biol. Chem. 140, 899. 